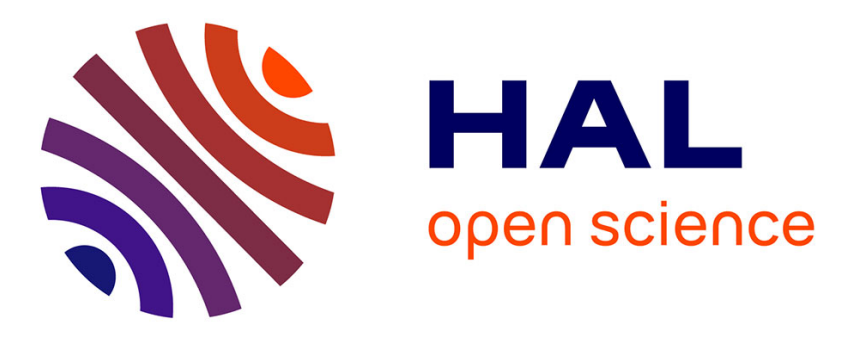

\title{
Role of the chemokine receptor CX3CR1 in the mobilization of phagocytic retinal microglial cells.
}

William Raoul, Nicole Keller, Mathieu Rodéro, Francine Behar-Cohen, Florian Sennlaub, Christophe Combadière

\section{- To cite this version:}

William Raoul, Nicole Keller, Mathieu Rodéro, Francine Behar-Cohen, Florian Sennlaub, et al.. Role of the chemokine receptor CX3CR1 in the mobilization of phagocytic retinal microglial cells.. Journal of Neuroimmunology, 2008, 198 (1-2), pp.56-61. 10.1016/j.jneuroim.2008.04.014 . inserm-00311574

\section{HAL Id: inserm-00311574 https://www.hal.inserm.fr/inserm-00311574}

Submitted on 19 Aug 2008

HAL is a multi-disciplinary open access archive for the deposit and dissemination of scientific research documents, whether they are published or not. The documents may come from teaching and research institutions in France or abroad, or from public or private research centers.
L'archive ouverte pluridisciplinaire HAL, est destinée au dépôt et à la diffusion de documents scientifiques de niveau recherche, publiés ou non, émanant des établissements d'enseignement et de recherche français ou étrangers, des laboratoires publics ou privés. 


\section{Role of the chemokine receptor CX3CR1 in the mobilization of phagocytic retinal microglial cells}

William Raoul ${ }^{1,2,3}$, Nicole Keller ${ }^{1,2,3}$, Mathieu Rodéro ${ }^{4,5}$, Francine Behar-Cohen ${ }^{1,2,3,6}$, Florian Sennlaub $b^{1,2,3^{*}}$ and Christophe Combadière ${ }^{4,5,7^{*}}$

${ }^{1}$ INSERM, UMR S 872, Centre de Recherche des Cordeliers, F-75005, Paris, France

${ }^{2}$ UPMC Univ Paris 06, UMR S 872, F-75005, Paris, France

${ }^{3}$ Université Paris Descartes, UMR S 872, F-75005, Paris, France

${ }^{4}$ INSERM U543, Laboratoire d'Immunologie Cellulaire, F-75005, Paris, France

${ }^{5}$ UPMC Univ Paris 06, F-75005, Paris, France.

${ }^{6}$ AP-HP, Hôtel Dieu, Service d'Ophtalmologie, Centre de Recherche Ophtalmologique, Paris, France.

7 AP-HP, Groupe hospitalier Pitié-Salpétrière, Service d'Immunologie, F-75005, Paris, France.

* FS and CC contributed equally to this work.

To whom correspondence should be addressed at: 1) Dr William Raoul, INSERM UMR S 872, équipe 17, Centre de Recherche des Cordeliers, 15 rue de l'Ecole de Médecine, 75006

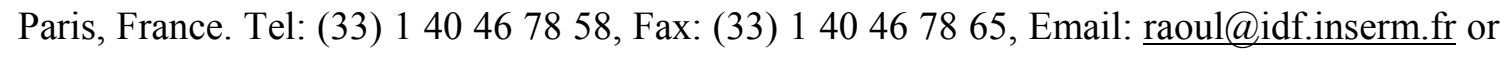
2) Dr Christophe Combadière, INSERM U543, Faculté de Médecine Pitié-Salpétrière, 91 Boulevard de l'Hôpital, 75013 Paris, France. Tel: (33) 1407798 92, Fax: (33) 140779734 , Email: $\underline{\text { combad@,ccr.jussieu.fr }}$ 
Short Running Title: CX3CR1 in the mobilization of phagocytic retinal microglial cells

This work was supported by grants from INSERM, ANR "Cardiovasculaire, obésité et diabète" (AO5088DS), ANR “blanc" (AO5120DD), European Grant "Innochem” (LSHB-CT2005-518167), PNR vision (AO6004SP) and by the Fondation NRJ-Institut de France. C.C. is a recipient of a contract «Interface» from Assistance Publique-Hopitaux de Paris. W.R. received a fellowship from ANR "Blanc" (AO5120DD). 


\begin{abstract}
We recently showed that subretinal CX3CR1-dependent microglial cell (MC) accumulation may lead to age-related macular degeneration. The fate of $\mathrm{MC}$ after engulfing retinal debris is poorly understood. Severe photoreceptor degeneration was observed 40 days after exposure to bright light in CX3CR1-deficient but not control mice, and more MCs accumulated in the subretinal space of the former than the latter. To study the fate of subretiinal MCs in CX3CR1 competent animals we used a dystrophic rat model, in which abundant subretinal MC accumulation is observed secondary to primary retinal degeneration. In dystrophic rats, MCs containing rhodopsin or rod outer segment (ROS) debris were found outside the outer retina at sites suggesting choroidal and ciliary egress. In conclusion, our data indicate that $\mathrm{MC}$ accumulation at injury sites is independent of CX3CR1 and precedes photoreceptor degeneration. The ectopic presence of rhodopsin-positive MCs suggest that CX3CR1 participates in MC egress from the outer retina.
\end{abstract}

\title{
1. Introduction
}

Age-related macular degeneration (AMD) is the leading cause of vision loss in the elderly throughout the industrialized world (Friedman et al., 2004). Its most prominent pathologic features are lesions involving the retinal pigment epithelium (RPE) and Bruch's membrane (BM), the degeneration of photoreceptors (Sarks, 1976) and, in the most aggressive cases, choroidal neovascularization. The causes of AMD are not well understood, but epidemiological studies and murine models have identified key factors in its pathogenesis. The main predisposing factors for its onset are age (Friedman et al., 2004) and family history (Bird et al., 1995). Increasing evidence suggests that retinal microglial cells (MCs) and alterations in chemokine pathways play a major role in its development (Ambati et al., 2003; Combadière et al., 2007; Pham et al., 2005). 
Chemokines are well-described proinflammatory cytokines that coordinate the deployment and activation of leukocytes at injury sites by signaling through a family of $G$ protein-coupled receptors (Luster, 1998). There is growing evidence that they are not restricted to leukocyte trafficking from the blood to tissues but rather are multifunctional mediators acting on various cell types, including resident cells such as epithelial, endothelial, and smooth muscle cells as well as neurons. Cell functions associated with chemokines are no longer limited to basic cell recruitment and now extend to angiogenesis, cell survival, cell proliferation and neurotransmission (Ransohoff et al., 2007). Drugs targeting them are among the most promising new anti-inflammatory treatments because they may be more selective than current anti-inflammatory drugs and less harmful than immunosuppressants.

Recently, we showed that the chemokine receptor CX3CR1 is expressed on all retinal MCs and that a defect in its function is associated with the risk of AMD (Combadière et al., 2007). CX3CR1-deficient mice developed cardinal features of AMD with resident MCs accumulating into the subretinal space. Photoreceptor cell degeneration occurred secondarily to the $\mathrm{MC}$ accumulation in the subretinal space, regardless of the retinal insult (aging and laser photocoagulation). The fate of MCs after they engulf retinal debris is poorly understood. We postulated that MCs in the subretinal space phagocytize degenerating rod outer segments (ROS) and may be then redistributed in the retina to clear debris into the vasculature. Here we used a model of bright light exposure to corroborate our previous findings in CX3CR1deficient mice and then tracked the fate of subretinal MCs further in a well-known rodent model: the dystrophic Royal College of Surgeons rats (RCS). 


\section{Materials and methods}

\subsection{Animals}

$\mathrm{CX} 3 \mathrm{CR} 1^{-/-}$and $\mathrm{CX} 3 \mathrm{CR} 1^{\mathrm{GFP} / \mathrm{GFP}}$ mouse strains on $\mathrm{C} 57 \mathrm{BL} / 6$ background and their $\mathrm{CX} 3 \mathrm{CR} 1^{+/+}$ controls were generated as described before (Combadiere et al., 2003; Jung et al., 2000). The mice were maintained at the "Centre d'Exploration Fonctionnelle" animal facility (PitiéSalpétrière, Paris) under pathogen-free conditions. Control C57BL/6 wild type mice (here referred as $\mathrm{CX} 3 \mathrm{CR} 1+/+$ ) were obtained from the Center d'Elevage Janvier (Le Genest St Isle, France). Royal College of Surgeon (RCS) rats were from our colony and were kept in specific pathogen-free conditions at the animal facility of University Paris V Descartes (Paris). All animals were housed in a 12/12 hour light/dark (100-500 lux) cycle with food and water available ad libitum. Animal experiments were approved by the Institutional Animal Care and Use Committee of the Faculté de Médecine Pitié-Salpétrière (Paris).

\subsection{Bright light exposure}

Mice were anesthetized by intraperitoneal injection of ketamine $(50 \mathrm{mg} / \mathrm{kg})$ and xylazine $(10$ $\mathrm{mg} / \mathrm{kg}$ ) from Bayer (Puteaux, France). Pupils were fully dilated with $1 \%$ tropicamide or $1 \%$ Atropin (Novartis, Rueil Malmaison, France). The mice were then exposed to bright light (100 Klux/eye) from a KL2500 LCD Schott lamp (Schott, Clichy, France), with the lightconducting glass fibers close to the dilated eyes for $10 \mathrm{~min}$.

\subsection{Immunohistochemistry}

Frozen sections were stained according to standard immunohistochemical procedures, as previously described (Checchin et al., 2006). The primary antibodies used were mouse antirhodopsin (Rho4D2, a gift from Dr. R.S. Molday, University of British Colombia, Canada), mouse anti-CD68 (ED1, Serotec, Cergy Saint Christophe, France) and mouse anti-GFP (Torrey Pines Biolabs, Houston, TX, USA). The lectins used were TRITC-conjugated BSA-1 
(Sigma-Aldrich, Saint Quentin Fallavier, France) and rhodamine phalloidin (Molecular Probes, Leiden, Netherlands). FKN antibodies Primary antibodies were revealed with the corresponding Alexa or phosphatase alkaline-coupled secondary antibodies (Molecular Probes) (followed by fast-red retrieval), and sections were counterstained with 4-6-diamino-2phenylindole (DAPI). Sections were viewed with a fluorescence microscope (BX51; Olympus, Rungis, France) or a confocal microscope (Zeiss LSM 510 laser scanning microscope, Le Pecq, France). Each immunostaining was repeated at least 3 times and staining omitting the primary antibody served as the negative control.

\subsection{Choroidal flatmounts and MC quantification}

Eyes were enucleated, fixed in 4\% PFA for 15 minutes at room temperature, and sectioned at the limbus; the cornea and lens were discarded. The retinas were carefully peeled from the RPE/choroid/sclera. Retinas and choroids were fixed for additional 15 minutes in methanol at $-20^{\circ} \mathrm{C}$ and incubated with the indicated primary and secondary antibodies. The choroids and retinas were radially incised, flatmounted and viewed with a fluorescence microscope (BX51; Olympus). MCs were counted on whole RPE/choroidal flatmounts up to the ciliary body and on the outer segment side of the retina. The surface of the RPE was measured and MC density calculated.

\subsection{Histology and electron microscopy}

Eyes were fixed in $2.5 \%$ glutaraldehyde of cacodylate buffer $(0.1 \mathrm{M}, \mathrm{pH} 7.4)$. After 1 hour, eye balls were dissected, fixed for another 3 hours, post-fixed in $1 \%$ osmium tetroxide in cacodylate buffer and dehydrated in graduated ethanol solution. The samples were included in epoxy resin and oriented. Semithin sections $(1 \mu \mathrm{m})$, obtained with an ultramicrotome Reichert Ultracut E (Leica, Rueil Malmaison, France), were stained with toluidine blue and examined with a light microscope to measure photoreceptor layer thickness $300-800 \mu \mathrm{m}$ from the optic nerve . Ultrathin sections $(80 \mathrm{~nm})$ were contrasted with uranyl acetate and lead citrate and 
observed in a JEOL 100 CX II electron microscope (JEOL, Tokyo, Japan) with 80 kV.

\subsection{Microglial cell migration assay}

Brain glial cell suspensions were obtained from brains of 5 donor $\mathrm{C} 57 \mathrm{BL} 6 / \mathrm{J}$ or $\mathrm{CX} 3 \mathrm{CR} 1^{-/-}$ mice. Brains were isolated, freed of meninges and put into a $5 \% \mathrm{CO}_{2} / 37^{\circ} \mathrm{C}$ incubator for 15 min. The tissue was minced mechanically and flushed several times with a 1-ml pipette. Pooled minced tissue was harvested in PBS, and cells were centrifuged at $2000 \mathrm{rpm}$ for 10 min. The pellet was resuspended in fresh medium, and floating cells were separated from debris by decantation. This process was repeated 3 times. Harvested cells were centrifuged again. Finally, $200 \mu 1$ of cell suspension (1.5 million glial cells, about $1 / 10$ microglial cells) was placed in each of $5 \mu \mathrm{m}$ pore polycarbonate Transwell inserts with 5 - $\mu \mathrm{m}$ pores (Corning, Avon, France). CX3CL1, CCL2 and CCL5 (R\&D Systems, Lille, France) were used in 24well plates at concentrations of 0.5 to $50 \mu \mathrm{M}$ (dilution in DMEM medium, GIBCO BRL, Life Technology, Paisley, Scotland). Media in wells with chemokines (Peprotech, Rocky Hill, NJ) were harvested 1 day later and analyzed by flow cytometry (FACSCalibur, Becton Dickinson) for the CD11b marker (clone M1/70, BD Pharmingen, San Diego, CA, USA).

\subsection{Statistical Analysis}

Graph Pad Prism 4 (GraphPad Software, San Diego, CA, USA) was used for the data analysis and graphic representations. All values are reported as means \pm SEM. Statistical comparisons used unpaired two-sample $t$-tests for means and the Mann-Whitney U test. Significance was set at $\mathrm{p}<0.05$. 


\section{Results and Discussion}

\subsection{MC accumulation precedes photoreceptor degeneration in $\mathrm{CX}_{3 \mathrm{CR}}{ }^{-/-}$mice}

We previously showed that photoreceptor cell degeneration occurred secondarily to the $\mathrm{MC}$ accumulation in subretinal space in both chronic (aging) and aggressive acute (laser photocoagulation) models of retinal insult. We sought to replicate these results in a less aggressive model of acute light insult that, unlike laser photocoagulation, does not promote angiogenesis. $\mathrm{C} 57 \mathrm{Bl} / 6$ control and $\mathrm{CX} 3 \mathrm{CR}^{-/-}$mice were exposed to a short period of very bright light. After 40 days, the mice were euthanized and their retinas stained with toluidine blue as shown in Figure 1. A marked degeneration of photoreceptors was observed in the $\mathrm{CX} 3 \mathrm{CR} 1^{-/-}$mice exposed to bright light (Fig. 1B), compared with control mice (Fig. 1A) and control unexposed mice (data not shown). Measurements of photoreceptor cell layer thickness showed significant thinning $(\sim 50 \%)$ of the photoreceptor cell layer in the $\mathrm{CX} 3 \mathrm{CR} 1^{-/}$mice compared with control whereas cell layer thickness were similar in unexposed $\mathrm{CX} 3 \mathrm{CR}^{-/-}$and $\mathrm{CX} 3 \mathrm{CR} 1^{+/+}$mice (Fig. 1C) modifier la figure $1 \mathrm{C}$ et réajuster par rapport a jour $40 .$. These data indicate that $\mathrm{CX} 3 \mathrm{CR} 1^{-/-}$mice are much more sensitive to light exposure and that $\mathrm{CX} 3 \mathrm{CR} 1$ may participate in photoreceptor survival.

To track the CX3CR1-expressing cells, we repeated these experiments in CX3CR1 $1^{\mathrm{GFP} / \mathrm{GFP}}$ mice in which the GFP is driven by the CX3CR1 promoter. Ten days after light injury, CX3CR $1^{+/ G F P}$ mice displayed only occasional GFP-positive MCs adjacent to the RPE monolayer (red fluorescence in Fig. 2A), compared with the CX3CR1 ${ }^{\mathrm{GFP} / \mathrm{GFP}}$ mice, which showed a massive MC accumulation (Fig. 2B). Before light injury, the number of subretinal MC were similarly low in two-months old CX3CR $1^{+/ \mathrm{GFP}}$ and $\mathrm{CX} 3 \mathrm{CR} 1^{\mathrm{GFP} / \mathrm{GFP}}$ mice (Fig.2C). In $\mathrm{CX} 3 \mathrm{CR} 1^{+/ \mathrm{GFP}}$ mice, MCs were present in the subretinal space as early as one day after light 
exposure, and their number remained unchanged for 40 days (Fig. 2C). MC accumulation in $\mathrm{CX} 3 \mathrm{CR} 1^{\mathrm{GFP} / \mathrm{GFP}}$ intensified early, on the other hand, peaking at day 10 and slowly returning to baseline by day 40. A more detailed analysis of MC morphology in bright light-exposed pigmented $\mathrm{CX} 3 \mathrm{CR} 1^{+/ \mathrm{GFP}}$ and $\mathrm{CX} 3 \mathrm{CR} 1^{\mathrm{GFP} / \mathrm{GFP}}$ mice revealed small cell bodies with long, thin pseudopodia 1 day and 10 days after light exposure in the $\mathrm{CX} 3 \mathrm{CR} 1^{+/ \mathrm{GFP}}$ mice (Fig. 2D). In contrast, in the MCs of the $\mathrm{CX} 3 \mathrm{CR} 1{ }^{\mathrm{GFP} / \mathrm{GFP}}$ mice, the average cell body increased significantly in size by day 10 and the cells appeared bloated with intracellular inclusions (Fig. 2E). Quantification of the ratio of body size and pseudopodia length showed an increase in body size in the CX3CR $1^{\mathrm{GFP} / \mathrm{GFP}}$ mouse cells that was not observed in $\mathrm{CX} 3 \mathrm{CR} 1^{+/ \mathrm{GFP}}$ mice (Fig. 2F). Nevertheless, some MCs in CX3CR $1^{\mathrm{GFP} / \mathrm{GFP}}$ mice at day 10 had the slim body and long pseudopodia phenotype observed at day 1 and in control mice.

We previously showed that body growth in MCs may be attributed to ROS ingestion and lipid accumulation (Combadière et al., 2007). Our observations suggested that the average duration of time that $\mathrm{CX} 3 \mathrm{CR} 1^{\mathrm{GFP} / \mathrm{GFP}} \mathrm{MCs}$ spend in the subretinal space is longer than for controls. The accumulation of MCs in CX3CR1-deficient mice may therefore be due to their defective clearance from the subretinal space. This additional time may favor MC phagocytic functions and their transformation into bloated "foam cells". The transient occurrence of MCs in this bright-light model and in our experiments with albino CX3CR1 $1^{-/-}$mice (Combadière et al., 2007), together with the observation by $\mathrm{Ng}$ et al. (Ng and Streilein, 2001), suggests that retinal MCs may leave the subretinal space.

\subsection{MC migrated in response to inflammatory chemokines}

To evaluate the role of the $\mathrm{CX} 3 \mathrm{CL} 1 / \mathrm{CX} 3 \mathrm{CR} 1$ axis in $\mathrm{MC}$ redistribution, we studied CX3CL1 expression in 12-month-old CX3CR1 $1^{+/+}$mice (Fig. 3A). CX3CL1 (red stain) was strongly expressed in the major vessels of the retina and choroid (arrows). When the primary antibody was omitted, this staining was not observed in adjacent sections (Fig. 3B). No or 
very faint CX3CL1 staining was found in the photoreceptor layer, where the MCs accumulated in $\mathrm{CX} 3 \mathrm{CR} 1^{-/-}$mice. To assess the role of the chemokine pathway in $\mathrm{MC}$ redistribution, we performed an in vitro migration assay on single-cell suspensions of MCs from the brains of $\mathrm{CX} 3 \mathrm{CR} 1^{+/+}$and $\mathrm{CX} 3 \mathrm{CR} 1^{-/-}$mice (Fig. 3C). In cell suspensions from CX3CR $1^{+/+}$brains, CD11b-positive MCs migrated specifically in response to CX3CL1, CCL2 and CCL5 at concentrations ranging from $0.1 \mathrm{nM}$ to $50 \mathrm{nM}$ (Fig. 3C and data not shown). As expected, MC migration in the $\mathrm{CX} 3 \mathrm{CR} 1^{-/-}$mice was totally blunted in response to CX3CL1 but remained unchanged in response to CCL2 and CCL5. These findings suggest that the CX3CR1/CX3CL1 axis is not involved in MC redistribution to the subretinal space but may be required for further movement in or outside the retina.

\subsection{Rhodopsin-positive MCs exit the subretinal space by different routes}

The failure of studies in retinal degeneration models to detect TUNEL-positive cells in the subretinal space suggests that MCs, unlike photoreceptors, do not disappear by apoptosis (Tso et al., 1994). We hypothesized that MCs actively leave the subretinal space by migration. As MC phagocytize ROS, they become rhodopsin-positive and can be tracked outside the photoreceptor cell layer for as long as the intralysosomal antigen is recognized by the rhodopsin-specific antibody. In humans, MCs migrate into the inner retina after engulfing injured ROS in AMD (Gupta et al., 2003; Combadière et al., 2007). As subretinal MCs did not accumulate significantly in the light induced model in $\mathrm{CX} 3 \mathrm{CR} 1^{+/+}$mice this model, we found it not suitable to monitor the fate of subretinal in CX3CR1 competent MCs. Instead we used the model of dystrophic RCS rats, where MCs accumulate secondary to photoreceptor degeneration caused by a genetic defect (Roque et al., 1996). Dystrophic 35-day-old RCS rats displayed rhodopsin-positive cells (red fluorescence) expressing the microglial cell marker CD68 (green fluorescence) outside the photoreceptor cell layer — in the inner nuclear layer (Fig. 4A, B and C) and in the choroid (Fig. 4D, E and F). Furthermore, transmission electron 
microscopy of sections of dystrophic RCS rat retina (but not of control rat retina) showed the presence of cells in the lumen of choriocapillaries with the characteristic appearance of intralysosomal ROS remnants (Fig. 5A). Ultrastructural analysis confirmed the presence of both the early (Fig. 5B) and late (Fig. 5C) stages of ROS degradation, which are usually observed only in RPE cells. Taken together, our data show that cells positive for MC markers and containing ROS/rhodopsin can be found outside the photoreceptor cell layer, the exclusive site of physiological rhodopsin expression. The presence of rhodopsin-positive SrMCs in the inner retina suggests an exit via the retinal vessels, and their presence in the choroids points to an exit route through the choroid or ciliary body.

\section{Conclusions}

MCs in CX3CR1-deficient mice after bright light injury migrated to the subretinal space where they accumulate in a CX3CR1 independent way. Secondarily to this accumulation, photoreceptor cells degenerated in these mice. To investigate the fate of CX3CR1 competent subretinal MCs we used dystrophic RCS rats, where important subretinal MCs accumulations are found secondarily to primary photoreceptor degeneration. Detection of ROS debris containing mononuclear cells outside the photoreceptor cell layer in dystrophic RCS rats suggests that MCs actively migrate away from their subretinal location. The absence of these ectopic rhodopsin positive MCs in models of CX3CR1-deficient MC accumulation suggests a role of CX3CR1 in this process. These results describe a new clearance route that will necessitate further investigation to clarify and detail its mechanisms.

\section{Acknowledgements}

We thank Dr. D. Littman and Dr. S Jung for sharing the CX3CR1Kin GFP mice and Dr. R.S. Molday for the monoclonal anti-rhodopsin Rho4D2 antibody. 


\section{References}

Ambati, J., Anand, A., Fernandez, S., Sakurai, E., Lynn, B.C., Kuziel, W.A., Rollins, B.J., Ambati, B.K., 2003. An animal model of age-related macular degeneration in senescent Ccl-2- or Ccr-2-deficient mice. Nat Med 9, 1390-1397.

Bird, A.C., Bressler, N.M., Bressler, S.B., Chisholm, I.H., Coscas, G., Davis, M.D., de Jong, P.T., Klaver, C.C., Klein, B.E., Klein, R., et al., 1995. An international classification and grading system for age-related maculopathy and age-related macular degeneration. The International ARM Epidemiological Study Group. Surv Ophthalmol 39, 367-374.

Checchin, D., Sennlaub, F., Levavasseur, E., Leduc, M., Chemtob, S., 2006. Potential role of microglia in retinal blood vessel formation. Invest Ophthalmol Vis Sci 47, 3595-3602.

Combadière, C., Feumi, C., Raoul, W., Keller, N., Rodéro, M., Pézard, A., Lavalette, S., Houssier, M., Jonet, L., Picard, E., Debré, P., Sirinyan, M., Deterre, P., Ferroukhi, T., Cohen, S., Chauvaud, D., Jeanny, J.-C., Chemtob, S., Behar-Cohen, F., Sennlaub, F., 2007. CX3CR1-dependent subretinal microglia cell accumulation is associated with cardinal features of age-related macular degeneration. Journal of Clinical Investigation 117(10):2920-8.

Combadiere, C., Potteaux, S., Gao, J.L., Esposito, B., Casanova, S., Lee, E.J., Debre, P., Tedgui, A., Murphy, P.M., Mallat, Z., 2003. Decreased atherosclerotic lesion formation in CX3CR1/apolipoprotein E double knockout mice. Circulation 107, 10091016.

Friedman, D.S., O'Colmain, B.J., Munoz, B., Tomany, S.C., McCarty, C., de Jong, P.T., Nemesure, B., Mitchell, P., Kempen, J., 2004. Prevalence of age-related macular degeneration in the United States. Arch Ophthalmol 122, 564-572.

Gupta, N., Brown, K.E., Milam, A.H., 2003. Activated microglia in human retinitis pigmentosa, late-onset retinal degeneration, and age-related macular degeneration. Exp Eye Res 76, 463-471.

Jung, S., Aliberti, J., Graemmel, P., Sunshine, M.J., Kreutzberg, G.W., Sher, A., Littman, D.R., 2000. Analysis of fractalkine receptor CX(3)CR1 function by targeted deletion and green fluorescent protein reporter gene insertion. Mol Cell Biol 20, 4106-4114.

Luster, A.D., 1998. Chemokines--chemotactic cytokines that mediate inflammation. N Engl J Med 338, 436-445.

Ng, T.F., Streilein, J.W., 2001. Light-induced migration of retinal microglia into the subretinal space. Invest Ophthalmol Vis Sci 42, 3301-3310.

Pham, V.T., Wen, L., McCluskey, P., Madigan, M.C., Penfold, P.L., 2005. Human retinal microglia express candidate receptors for HIV-1 infection. Br J Ophthalmol 89, 753757.

Ransohoff, R.M., Liu, L., Cardona, A.E., 2007. Chemokines and chemokine receptors: multipurpose players in neuroinflammation. Int Rev Neurobiol 82, 187-204.

Roque, R.S., Imperial, C.J., Caldwell, R.B., 1996. Microglial cells invade the outer retina as photoreceptors degenerate in Royal College of Surgeons rats. Invest Ophthalmol Vis Sci 37, 196-203.

Sarks, S.H., 1976. Ageing and degeneration in the macular region: a clinico-pathological study. Br J Ophthalmol 60, 324-341. 
Tso, M.O., Zhang, C., Abler, A.S., Chang, C.J., Wong, F., Chang, G.Q., Lam, T.T., 1994. Apoptosis leads to photoreceptor degeneration in inherited retinal dystrophy of RCS rats. Invest Ophthalmol Vis Sci 35, 2693-2699. 


\section{Figure Legends}
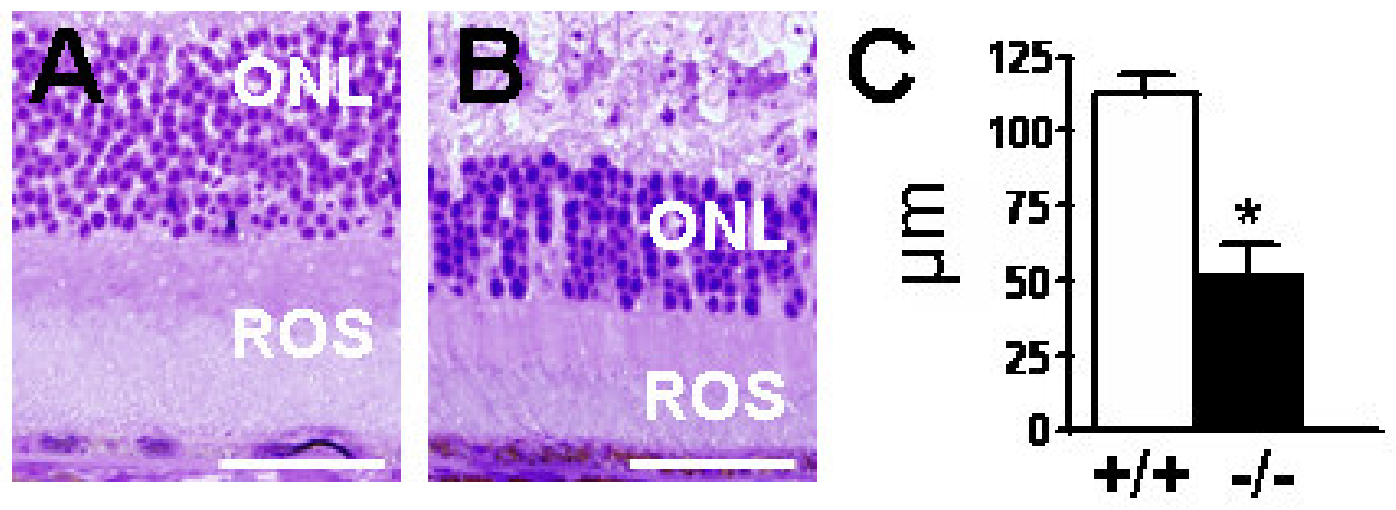

Figure 1: Photoreceptor degeneration after bright light injury in CX3CR1-/- mice.

Toluidine blue-stained epoxy retinal semithin sections of $\mathrm{CX} 3 \mathrm{CR} 1^{+/+}(\mathrm{A})$ and $\mathrm{CX} 3 \mathrm{CR} 1^{-/-}$(B) show degeneration of photoreceptors in $\mathrm{CX}_{3} \mathrm{CR} 1^{-/}$bright light-exposed mice. (C) Measurements of photoreceptor cell layer thickness show significant thinning of the photoreceptor cell layer in $\mathrm{CX} 3 \mathrm{CR}^{-/-}$mice. Experiments were performed on 4 to 8 eyes from different mice for C57BL/6 mice (+/+, empty columns) and CX3CR1 $1^{-/-}$(-/-, plain columns). *, $P<0.05$. ONL: outer nuclear layer; ROS: rod outer segments. Scale bars: $50 \mu \mathrm{m}$.
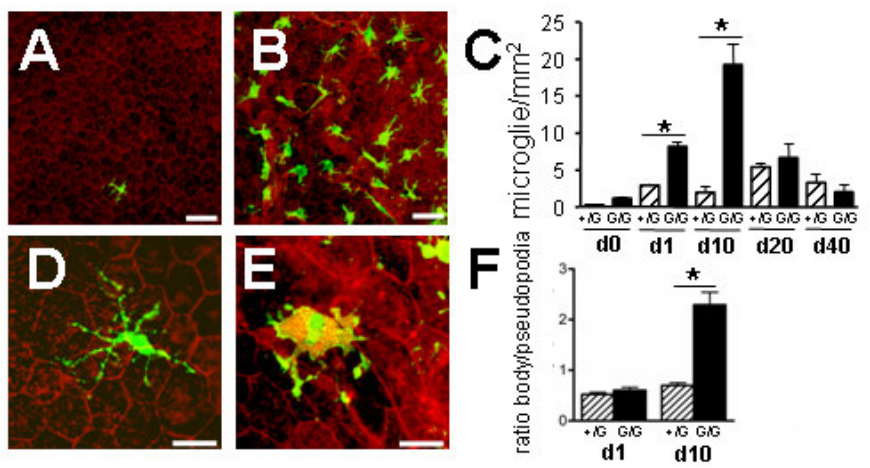

Figure 2: MC accumulate in the subretinal space after bright-light injury in CX3CR1-/mice.

RPE flatmounts of $\mathrm{CX} 3 \mathrm{CR} 1^{+/ \mathrm{GFP}}$ (A) and $\mathrm{CX} 3 \mathrm{CR} 1^{\mathrm{GFP} / \mathrm{GFP}}$ (B) show a substantial accumulation of subretinal MCs in $\mathrm{CX} 3 \mathrm{CR} 1^{\mathrm{GFP} / \mathrm{GFP}}$ mice in the bright light-exposure model. 
(C) Quantification of subretinal GFP cells on RPE flatmounts reveals a substantial accumulation of subretinal MC in CX3CR1-/- mice. Magnification of individual cells of bright light-exposed eyes reveals that subretinal MCs at day 10 after exposure of CX3CR $1^{\text {GFP/GFP }}$ (D) have large cell bodies and short pseudopodia compared with cells of $\mathrm{CX} 3 \mathrm{CR} 1^{+/ \mathrm{GFP}}$ mice (E). (F) Measurements of the ratio of the cell body versus the pseudopodia at $\mathrm{d} 1$ and $\mathrm{d} 10$ reveal that the bodies of $\mathrm{CX} 3 \mathrm{CR} 1^{\mathrm{GFP} / \mathrm{GFP}}$ subretinal cells increase in size with time after bright light exposure. Experiments were performed on 4 to 8 eyes from different mice for CX3CR1 $1^{+/ G F P}\left(+/ G\right.$, hatched columns) and $\mathrm{CX} 3 \mathrm{CR} 1^{\mathrm{GFP} / \mathrm{GFP}}(\mathrm{G} / \mathrm{G}$, plain columns). *, $P<0.05$. Scale bars: $50 \mu \mathrm{m}$. 

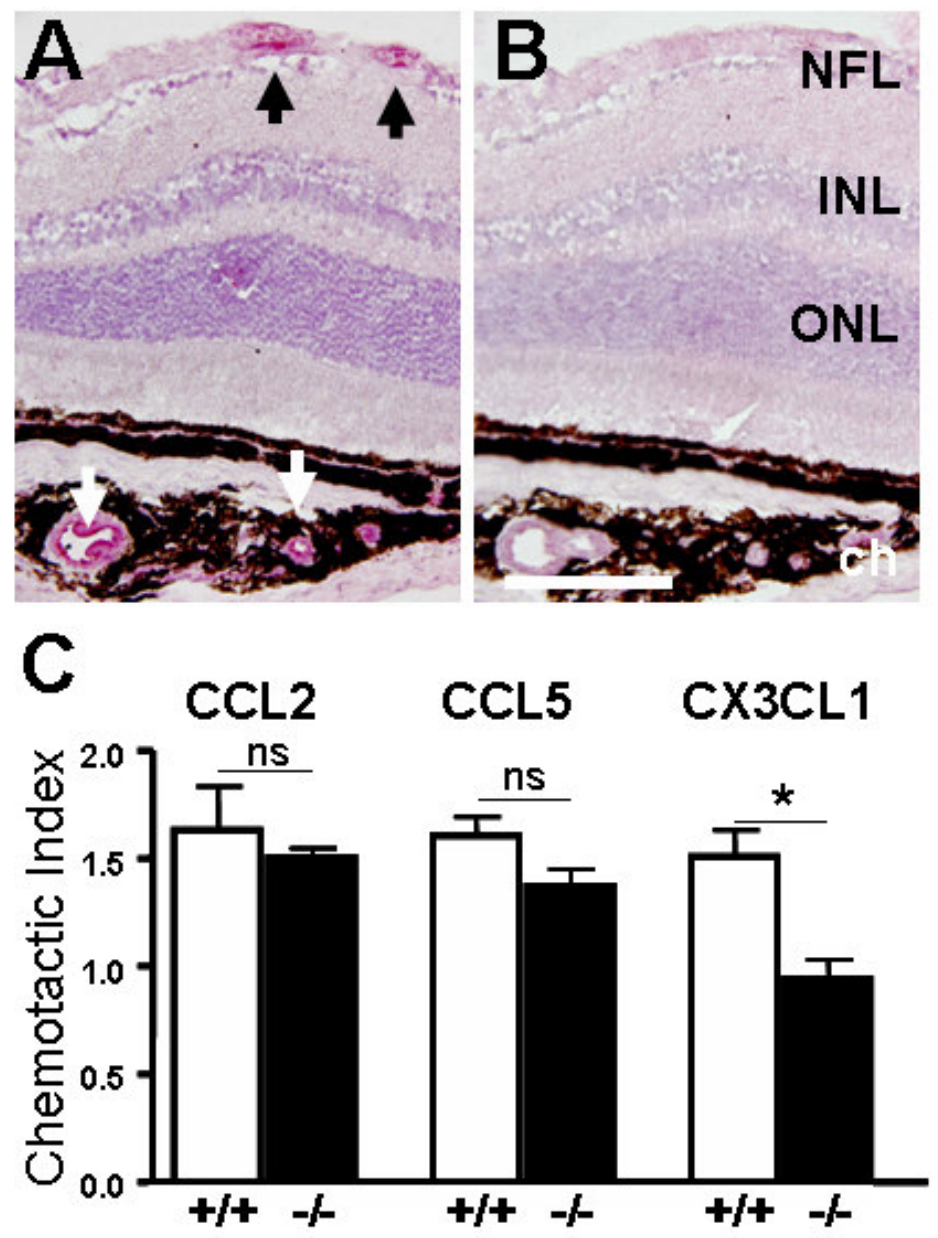

Figure 3: Localization of the chemokine CX3CL1 and in vitro migration assay.

(A) In C57BL/6 mice, CX3CL1 (red staining) localizes to the major vessels of the retina and choroid (arrows). (B) Negative control omitting the primary antibody. NFL: nerve fiber layer; INL: inner nuclear layer; ONL: outer nuclear layer; ch: choroids. Scale bar $100 \mu \mathrm{m}$. (C) In vitro migration assays of brain microglial cells compare chemotactic responses to $10 \mathrm{nM}$ of the indicated chemokines in $\mathrm{CX} 3 \mathrm{CR}^{-/-}$(plain columns) to $\mathrm{C} 57 \mathrm{BL} / 6$ (empty columns) groups of mice. Results are representative of at least three independent experiments. 

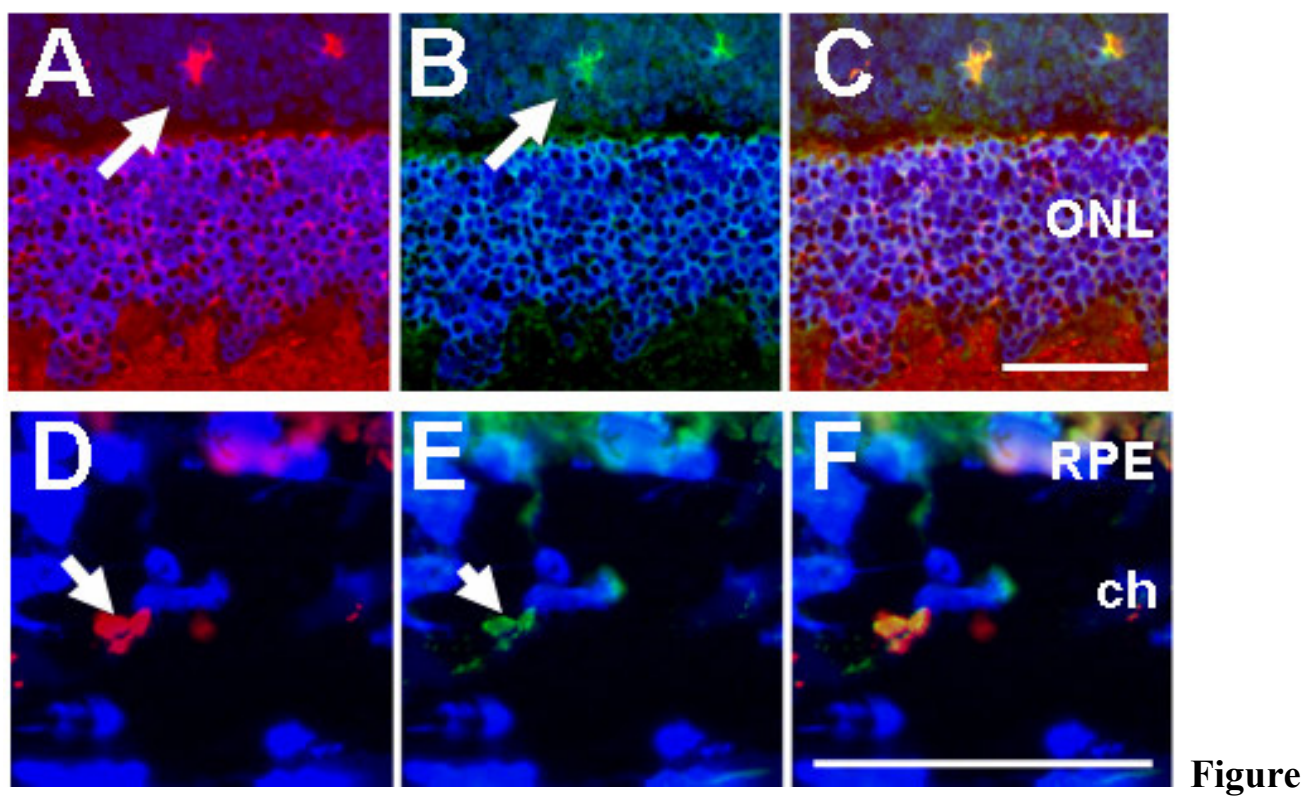

Rhodopsin-positive cells are found outside the PRL.

Dystrophic 35-day-old RCS rats display rhodopsin-positive cells (A and D, red fluorescence) expressing the microglial cell marker CD68 (B and E, green fluorescence) outside the photoreceptor cell layer in the inner retina (A, B and C for overlay) and in the choroid (D, E and $\mathrm{F}$ for overlay). Results are representative of at least three independent experiments. ONL: outer nuclear layer; RPE: retinal pigment epithelium. Ch: choroid. Scale bars : $50 \mu \mathrm{m}$.

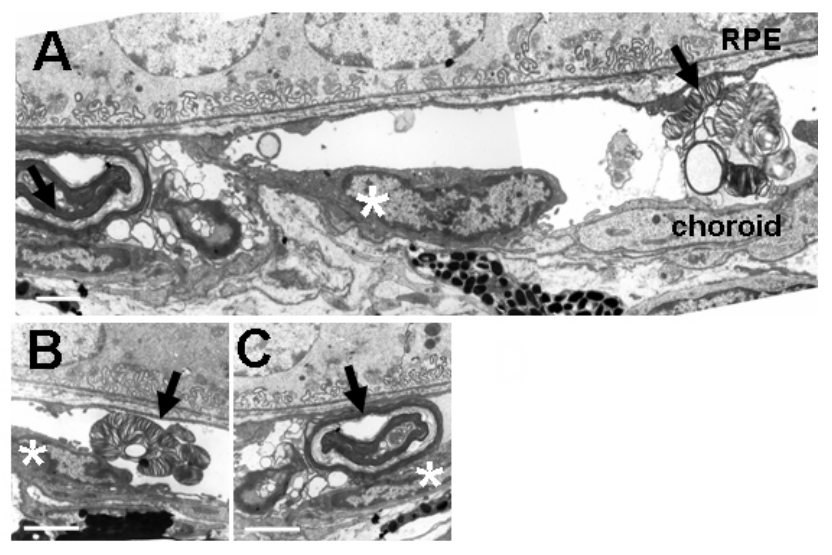

Figure 5 : ROS remnants in electron microscopy.

(A) Electron microscopy of choroidal vessels of dystrophic rat retina show intraluminal cells (stars) with degrading intralysosomal outer segments (arrows). Ectopic MC show intracellular 
intralysosomal remnants of the outer segment at early (B) and late (C) stages of degradation. Results are representative of at least four independent experiments. RPE: retinal pigment epithelium. Ch: choroid. Scale bars: $2 \mu \mathrm{m}$. 